\title{
Seafood Perceptions among People Aged 55 and Above: Summary of Focus Groups Results ${ }^{1}$
}

\author{
Allen F. Wysocki, Lisa House, and William A. Messina Jr. ${ }^{2}$
}

\section{Introduction}

Seafood contains nutritionally valuable nutrients, the most notable of which is Omega-3 fatty acids. The benefits of Omega-3 fatty acids have been thoroughly studied, with research showing they can help lower blood pressure, reduce the chance of heart disease, and reduce the incidence of dementia and Alzheimer's disease. The case for these benefits is strong enough that many of the U.S. premiere health organizations recommend the consumption of seafood as a preventative measure for disease. The American Heart Association recommends the consumption of seafood at least twice a week to prevent heart disease and as a benefit for those who have heart disease. In addition, the Alzheimer's Association recommends the consumption of cold-water fish species to help prevent Alzheimer's disease.

Although the health benefits of seafood are well documented, the manner in which messages about its good effects reach consumers aged 55 and older is less well known, and it is unclear how the messages influence older consumers' seafood consumption decisions. While significant research has been conducted on seafood consumption, little of it has focused on the 55 and above age group, an age group with much potential to gain from the consumption of seafood. In 2007, an effort to help the seafood industry develop a deeper understanding of the nutritional preferences and buying habits of this age group, the University of Florida, Institute of Food and Agricultural Sciences' (UF/IFAS) Florida Agricultural Market Research Center (FAMRC), with the support of the Florida Department of Agriculture and Consumer Services Bureau of Seafood and Aquaculture Marketing, launched a study of the perceptions of Florida residents aged 55 and over on seafood consumption. As an initial step in this research project, focus groups were conducted in Hillsborough, Miami-Dade, and Palm Beach Counties to gain insight into seafood consumption patterns and perceptions and to facilitate the construction of a detailed telephone summary. This report is a brief summary of the focus group research; the full report is available online at http://www.fred.ifas.ufl.edu/agmarketing/pubs/2000s/ seafood_perceptions.pdf. The remainder of this document will outline the methodology used and the present the key findings of the focus group study.

\section{Methodology}

Focus groups are commonly used in marketing research. By its very nature, focus group work is not designed to prove statistical validity or causal relationships. The power of focus group research is its ability to discover the motivations driving the purchasing behavior of target audience consumers. Participants are typically individuals in the

1. This document is FE821, one of a series of the Food and Resource Economics Department, Florida Cooperative Extension Service, Institute of Food and Agricultural Sciences, University of Florida. Original publication date November 2009. Reviewed March 2013. Visit the EDIS website at http://edis.ifas. ufl.edu.

2. Allen F. Wysocki, associate professor and coordinator of Agribusiness Masters program; Lisa House, professor and director of Florida Agricultural Market Research Center (FAMRC); and William A. Messina Jr., economic analyst, Florida Agricultural Market Research Center (FAMRC), Food and Resource Economics Department, Florida Cooperative Extension Service, Institute of Food and Agricultural Sciences, University of Florida, Gainesville, FL 32611. This project was supported by the National Needs Fellowship Program of the Cooperative State Research, Education and Extension Service, USDA, Grant \#2005-38420-15781 and the Florida Department of Agriculture and Consumer Services. 
target population. Focus groups let participants react to information in a semi-structured environment. Discussion guidelines and well established techniques help minimize bias. The objective is to gain the most detailed insight possible regarding the opinions of focus group participants in a short period of time. Focus group research is not used to collect large amounts of data, but as an input into a deeper understanding of consumer tastes and perceptions. To use focus groups alone to tackle the task of understanding consumer attitudes would not be a cost-efficient method, nor would it be likely to produce results that are representative of the general population. However, when used in combination with future quantitative analysis, such as a telephone survey, focus groups can provide the needed input for developing questions.

In this study, six focus groups were held in Florida, four in Palm Beach and Miami-Dade Counties (Miami area) and two in Hillsborough County (Tampa area), in October and November of 2007. Each focus group consisted of between 7 and 10 participants and lasted for about 90 minutes. These groups were designed to get participants to think about and discuss in-depth the how, when, where, how-often, and why behind their decisions whether or not to purchase seafood. This was accomplished by the following focus group agenda:

- Introductions (to build rapport)

- Ice breaker (to help participants focus on seafood-participants were given a list of words to react to in a word association game)

- Discussion of seafood consumption (To better understand how, when, where, how-often, and why consumers purchase products in the seafood category-included discussions regarding consumption sites, forms of seafood consumed, types of seafood they could recall, food/nutrition concerns, most important criteria for seafood purchase decision, factors that affect seafood consumption, and if respondents care where their seafood comes from)

- Advice focus group participants would give to the seafood industry (to elicit advice from participants about how the seafood industry could increase seafood consumption)

- Brief demographic questionnaire (to quantify selected demographic variables of the participants)
- Wrap up (to answer any remaining questions participants might have and to further explain the purpose of this research)

This study targeted people 55 years of age and older, with an effort made to obtain focus group participants across the 55- to 75-year-old range. Participants were recruited randomly using a professional market research firm. Focus groups at each location were split into sub-groups comprised of seafood consumers and seafood non-consumers. Depending on the location, the group of non-consumers either consisted of true non-consumers (those who never eat seafood) or light consumers (those who eat seafood only on rare occasions). Table 1 provides a demographic description of the focus groups.

Focus group participants (primary shoppers in their households) were predominantly female, and most participants were Caucasian (only 5 out of 55 focus group participants were non-white). The largest percentage $(30.7 \%)$ of focus group participants reported income in the range of $\$ 50,000$ to $\$ 100,000$ per year. The distribution of income is representative of the population in the Miami and Tampa areas for this age group.

\section{Word Association Findings}

Participants were asked to respond to a series of words and terms related to the consumption of seafood to set the stage for the rest of the focus group. When asked to respond to the words fish and shellfish, people who consume seafood quickly listed a number of specific species such as crab, grouper, lobster, salmon, shrimp, and snapper. Those who were light or non-consumers spoke of unpleasant experiences, smelly fish, and getting sick from consuming seafood.

When asked about catfish, the participants were mixed in their views. Some labeled catfish positively as a delicacy, while others labeled catfish negatively as a bottom feeder.

The term finfish confused some participants because they thought that all fish had fins. Therefore, the industry would do well to avoid using this term when dealing with the general public.

The term seafood was usually understood in the focus group to mean the combination of finfish and shellfish.

Wild caught meant better for you, fewer chemicals, and better tasting to some of the participants, while to other participants it meant paying more, uncertainty about 
mercury levels, and a gamier taste. Alaskan salmon was the most commonly associated wild caught seafood species.

The term farm-raised conjured up images of controlled environments and antibiotics by some participants because of media coverage about problems with farm-raised fish. Other participants viewed farm-raised seafood as a pure and clean product, one backed by considerable research and a product that is good for you.

Aquaculture is another term that does not easily communicate to consumers. Participants knew it had something to do with water. Some thought that it was about growing plants for aquariums. In general, there is a mixed reaction to farm-raised and a general lack of knowledge about aquaculture.

The term fresh brought out the greatest emotion in the participants. Fresh meant off the boat, to the customer's plate the same day. Fresh is what all participants strived for when selecting seafood for purchase or consumption.

If fresh is the holy grail of the seafood business, then processed is the opposite in the minds of consumers. Most participants associated processed with altering a product for the worse, taking all the good stuff out, using additives, or combining pieces of fish scraps to make a larger piece. While the majority of participants had a negative reaction, some knew that processing is an integral part of the seafood industry. There seems to be tolerance for processes such as flash freezing. There was some confusion because many participants thought they were purchasing fresh shrimp, when in fact they were purchasing processed shrimp using flash freezing.

Organic generally meant healthy and more natural to the participants, the way things used to be grown and raised before all these chemicals. Some participants were less enthusiastic about organic products, especially when discussing seafood. There was confusion as to what constitutes organic seafood. As one participant put it, "Isn't all wild-caught seafood organic?"

Perhaps the most interesting finding from the word association exercise was the lack of knowledge regarding sustainability. When asked what sustainable means, the majority of participants said it had to with increasing shelf life or maintaining flavor longer. The seafood industry would do well to educate consumers about the meaning of sustainability relative to seafood and the use of fishing/harvesting practices that will help to sustain the fisheries populations before using this wording on packaging.

\section{Discussion of Seafood Consumption}

Participants were asked to describe their seafood consumption attitudes and preferences. Participants from the Miami area were more likely to purchase seafood from specialty seafood houses than participants in the Tampa area. This may be due in part to the influence of the northeastern United States, where many of the Miami area participants were born and raised, compared to the upper Midwest roots for the participants from the Tampa area. Participants indicated that there were fewer specialty seafood houses in the Tampa area, compared to the Miami area which could be another factor influencing these purchasing patterns. When it comes to purchasing salmon, Costco has a specific and excellent reputation for quality and value.

Participants were split as to where they consume their seafood. Consuming seafood at restaurants has an edge over purchasing seafood to be prepared and consumed at home. There are a lot of factors that might explain this, including odors from cooking seafood and the perceived lengthy time it takes to prepare and cook seafood. Participants indicated they would be more likely to purchase shellfish at a restaurant than they would be to purchase it to take home to prepare it themselves.

The influence of others in a household on the purchasing or consumption habits of seafood had a definite impact as was expected. Most of the primary shoppers interviewed indicated they tried to accommodate the tastes and preferences of the people in their household when purchasing seafood. In some cases this meant not purchasing seafood because others in the household did not like the smell or taste of seafood.

Seafood-based traditions exist but do not appear to be as universal as other food-based traditions, such as turkey at Thanksgiving or ham at Easter. Seafood-based traditions included bakala, gefilte fish, seven fishes, boiled crabs, and gumbo.

When asked how seafood is best prepared produced a range of answers. In general, broiled or baked non-breaded fish filets were preferred by seafood consumers, while light consumers preferred breaded seafood. One might argue that the breading makes consuming the seafood more tolerable for light consumers.

Many of the participants believed they could meet fishing boats returning to the docks and purchase fresh fish directly from these boats. This is contradictory to state law, 
although in some cases these fishing boats may be owned by friends or family members who have caught seafood.

The focus group moderators attempted to see what role country-of-origin played in seafood purchases and consumption decisions. Where seafood comes from does matter in some cases. For example, seafood from China was always given the thumbs down. Much of this may be due to recent news stories of recalls from China. Impressions of seafood from Latin and South America depended on past experiences of the participants; generally, the participants were favorable but cautious, citing lack of knowledge of standards and procedures. Respondents' attitudes were very favorable towards seafood from Norway, Maine, and Alaska. When participants were asked about purchasing seafood from Florida waters, the reaction was usually positive, but not as strong as from a state like Alaska.

\section{Factors That Affect Seafood Purchases and Consumption}

A primary objective of the focus group process was to identify those factors that drive purchase and consumption of seafood.

A common theme, especially among light and nonconsumers was their awareness of the bad press relating to seafood. Stories of high levels of mercury or worries about the safety of the seafood caught in Florida waters strike doubt in the minds of these consumers. Thus, the industry can take a proactive role in educating consumers about seafood, from teaching differences between species to addressing health concerns.

Participants indicated that familiarity or lack of familiarity with a given seafood species drives purchase and consumption decisions. If they are unfamiliar with a given species, it does not matter what the price is, as they are unlikely to purchase or try it at a restaurant.

Another important factor in the purchase and consumption decisions of these participants is appearance. If the filet looks dried out or translucent, this signals lowered quality and, therefore, a no-buy decision.

The roles of tradition, past experiences, and habits are almost hard-wired into the purchase and consumption decisions of the surveyed participants. Stories of eating seafood that was over-cooked or getting sick after consuming seafood revealed deep emotions and represented a definite barrier to future sales. Interestingly, some focus group participants indicated that they have increased their consumption of seafood since moving to Florida, while others indicated they have not significantly changed their seafood eating habits. Most of the focus group participants have lived in Florida for more than 15 years and consider themselves Floridians.

For seafood consumers, the price of seafood tends to cause them to switch from one species of seafood to another instead of away from seafood. For the non-consumers, price is not an important factor, as they usually are not predisposed to purchasing or consuming seafood. Seafood consumers rely heavily on the reputation of specialty seafood houses, their regular grocery stores, and specialty seafood restaurants when deciding whether or not to purchase or consume seafood.

Taste, texture, and/or odor are important considerations for seafood consumers and non-consumers alike. For consumers, the right taste and odor signals the freshness and quality of a particular piece of seafood, and/or a decision of what species to buy verses not buying any seafood. For the non-consumer, taste and odor are constant reminders of why they do not consume more seafood, an obstacle that may be hard for the industry to overcome.

\section{Advice to the Seafood Industry}

Focus group participants were asked to put themselves into the role of consultants to the seafood industry and to state what advice they would give to increase seafood purchases and consumption.

All four categories (Miami area consumers, Miami area light consumers, Tampa area consumers, and Tampa area non-consumers) of the focus group participants felt that there needed to be more advertising on the health benefits and the wide variety of seafood available. Participants noted the various ways they obtain information, including newspapers, television, magazines, in-store demonstrations and programs such as the Aprons program at Publix, and internet-based newsletters delivered directly to individual e-mail inboxes.

The seafood industry would do well to increase the consistency of product (e.g., same-sized filets in a package) and knowledge of specific species for the parts of the industry that interact directly with consumers (e.g., people working for retailers and restaurants). Freshness was the most important factor with seafood, so successful companies should document their freshness and incorporate sources of inspections and certifications that consumers trust. Further research into how this trust could be effectively 
communicated is needed. The industry needs to work with retailers to improve the appearance and odor of fish counters. At the same time, retailers must not overpower seafood odor with a cleanser odor such as bleach, as this is a turnoff to consumers as well.

The industry should continue to find ways to educate consumers on differences regarding preparation, cooking, and potential uses on a species-by-species basis. When focus group participants were shown the species-specific information brochures created by the Florida Department of Agriculture and Consumer Services (FDACS), they responded very positively. They liked the fact the brochures had pictures (some debated whether to use pictures of whole fish or filets), safe handling instructions, and recipes.

\section{Concluding Remarks}

This was an important study for the seafood industry. The Florida Department of Agricultural and Consumer Services has increased the number of Florida seafood brochures available to the public as a result of this study.

This study focused on consumers aged 55 and older who were predominately female and Caucasian. It would be useful and interesting to conduct additional seafood studies with other consumer segments. Responses from a more diverse audience (based on race, gender, and age) could be compared to the results of this study and the implications of the findings shared with the seafood industry.

Table 1. Demographics of focus groups by location and seafood consumption preference.

\begin{tabular}{|lcc|}
\hline & Average consumption of seafood per week & Average age \\
\hline Miami Area Consumers & 2.1 times & 63 \\
Miami Area Light Consumers & 0.7 times & 60 \\
Tampa Area Consumers & 2.9 times & 62 \\
Tampa Area Non-Consumers & 0.1 times & 65 \\
\hline
\end{tabular}

